\title{
Studi Spatial Behavior Ruang Hunian Rumah Susun Studi Kasus Rumah Susun Sederhana Milik Tipe 36 di Jakarta
}

\author{
Noeratri Andanwerti ${ }^{1}$, Bambang Deliyanto ${ }^{2}$ \\ Fakultas Seni Rupa dan Desain, Universitas Tarumanagara ${ }^{1}$ \\ Program Studi Perencanaan Wilayah dan Kota, Universitas Terbuka ${ }^{2}$ \\ noeratria@fsrd.untar.ac.id
}

\begin{abstract}
Penelitian dilakukan dengan latar belakang terjadinya pembangunan yang sangat pesat di kota Jakarta yang memberikan dampak pada meningkatnya kebutuhan masyarakat akan rumah tinggal yang layak. Melalui penelitian mengenai perilaku manusia di rumah susun sederhana milik (rusunami) diharapkan mampu menjawab permasalahan manusia sebagai tolok ukur perancangan rusunami sebagai tempat tinggal yang layak. Penelitian ini bertujuan menemukan pola spatial behavior yang terjadi di area hunian pada rusunami. Pola tersebut nantinya akan dilanjutkan pada tahap penelitian berikutnya yakni pembuatan model behavior setting pada area hunian di fasilitas rusunami. Model behavior setting ini diharapkan nantinya mampu memecahkan masalah perancangan perilaku manusia dalam ruang pada area bersama di rusunami secara berkelanjutan. Penelitian ini mengambil lokasi di Jakarta, dengan studi kasus dipilih rusunami yang memiliki tipe ruang hunian tipe 36. Data primer didapat melalui metode sampling yang mencakup berbagai kriteria seperti demografi, latar belakang sosial, pendidikan, dan jenis/tipe unit hunian yang dimiliki melalui observasi penelusuran fisik dan observasi perilaku penghuni. Data ini kemudian dianalisa melalui metode analisis sistemik yang meliputi tahap-tahap penguraian dan penyusunan data, penyimpulan serta rumusan hasil penelitian berupa pola/konsep perancangan. Penelitian ini juga membutuhkan data sekunder yang diambil dari beberapa referensi dan pustaka yang terkait dengan permasalahan penelitian ini.
\end{abstract}

Kata kunci: rumah, susun, hunian, spatial, behavior

\section{PENDAHULUAN}

Pembangunan di Indonesia mengarah pada pembangunan di kota-kota besar yang ditandai dengan tumbuhnya industri dan jasa yang banyak membutuhkan tenaga kerja dan adanya urbanisasi. Pertumbuhan penduduk kota Jakarta yang semakin tinggi, terlihat pada data statistik tahun 2015 adalah 10,178 juta orang dan laju pertumbuhan penduduk per tahun 1,02 . Pertumbuhan penduduk yang semakin tinggi di kota Jakarta memberikan dampak yang serius terhadap ketersediaan kebutuhan pokok seperti pangan, sandang dan papan.
Penyediaan kebutuhan perumahan di Jakarta pada saat ini semakin sulit karena keterbatasan lahan. Nilai tanah yang semakin tinggi mendorong harga jual rumah semakin melambung dan sulit untuk dicapai oleh masyarakat menengah ke bawah. Pemerintah telah mencanangkan program pembangunan rumah susun sebagai jalan untuk menyediakan perumahan bagi rakyat. Rumah susun sederhana milik (rusunami) berupa bangunan bertingkat (vertikal) dengan karakteristik ruangnya merupakan hal yang baru bagi masayarakat yang terbiasa pada rumah tinggal konvensional (horizontal). 
Perilaku manusia merupakan respon manusia terhadap pengaruh lingkungan fisik. Pada proses interaksi masyarakat yang tinggal di rusunami dengan lingkungan barunya memberikan hasil berupa perilaku positif dan negatif. Dari beberapa penelitian yang telah dilakukan terhadap perilaku penghuni di rumah susun menunjukkan adanya perilaku negatif. Hal ini mendorong peneliti untuk mempelajari khususnya perilaku manusia terhadap unit hunian di rumah susun dan menyusun rumusan yang baru mengenai pola behavior setting yang tepat untuk memperkecil dampak perilaku negatif pada pembangunan rusunami secara berkelanjutan.

Tujuan dari penelitian ini secara khusus adalah (1) mengidentifikasi karakteristik penghuni rumah susun pada ruang hunian yang membawa implikasi terhadap konsep perancangan rusunami secara menyeluruh, (2) mendeskripsikan kondisi eksisting ruang dan perilaku manusia sebagai respon terhadap lingkungan fisik melalui evaluasi pasca huni, (3) mendeskripsikan aspek-aspek perilaku yang menjadi pertimbangan dalam proses perancangan ruang bersama di rusunami. (4) mendeskripsikan aspek perilaku tersebut terhadap perancangan ruang hunian ditinjau dari penataan ruang dan penataan furnitur, (5) merumuskan konsep rancangan unit hunian rumah susun tipe 36 yang memperhatikan karakteristik perilaku dan kondisi penghuni.

Spatial behavior menurut Laurens (2005) adalah cara bagaimana manusia menggunakan suatu setting lingkungan, atau dengan kata lain kemanfaatan (affordances) lingkungan. Spatial behavior merupakan wujud setting (tatanan) keruangan lingkungan dan fluktuasi elemen nonsensasi sistem keruangan akibat perilaku manusia dalam menggunakan atau memanfaatkan lingkungan tersebut (Deliyanto, 2010).

Manusia dalam memenuhi kebutuhannya seperti yang telah diuraikan dalam hierarki kebutuhan Maslow, manusia menciptakan ruang-ruang aktivitas yang terlihat dari pola perilaku penggunanya. Bell (1996) dan Krech (1962) melihat bahwa ada hubungan timbal balik antara lingkungan spasial yang terbentuk dan perilaku manusia, oleh karena itu pertemuan antara individu dan lingkungannya mewujudkan behavior setting.

Istilah behavioral setting oleh Roger Barker (1968) digunakan untuk menjelaskan kombinasi yang stabil antara perilaku dan milleu tertentu, sedangkan David Haviland (1967) menyebutkan kombinasi ini sebagai "ruang aktivitas" (Laurens, 2005). Contoh: 
setting ruang kelas, ruang rapat, mesjid, gereja, dan lain-lain. Behavior setting adalah pola perilaku kelompok, bukan perilaku individu, yang terjadi sebagai akibat kondisi lingkungan atau spatial tertentu yang disebut physical milieu (nilai ruang yang ditentukan oleh sistem aktivitasnya).

\section{METODE PENELITIAN}

Obyek penelitian adalah unit hunian rumah susun sederhana milik tipe 36 yang berada di blok Apron 1 (A1) dan Blok Apron 3 (A3) di Kota Baru Bandar Kemayoran. Ruang lingkup yang akan diurai adalah mencakup aspek fungsional (aktivitas), aspek kebutuhan fasilitas, dan perilaku penghuni dalam hubungannya dengan rancangan ruang dalam (interior) unit hunian rumah susun tipe 36. Aspek fungsional yang akan diurai adalah sistem aktivitas penghuni, kebutuhan fasilitas funitur, tata letak furnitur, pemilihan jenis furnitur

Penelitian ini menggunakan teknik cluster sampling untuk mendapatkan data primer, dengan memilih secara acak yang melibatkan 50 responden. Instrumen yang digunakan dalam penelitian ini adalah : (1) kuesioner, (2) formulir pencatatan karakteritik aktivitas penghuni, (3) penggambaran setting fisik hunian. Data penelitian diperoleh melalui metode observasi, dokumentasi, dan metode kuesioner. Cluster penghuni yang akan diteliti dengan memperhatikan karakteristik:

a. Kondisi sosial ekonomi: usia, pendidikan, pekerjaan, penghasilan, pengeluaran rumah tangga, status kepemilikan, lama menghuni

b. Karakteristik Fisik: luas unit hunian, kondisi fisik ruang hunian

c. Karakteristik Spasial Behavior: perilaku penghuni terhadap eksisting ruang, perilaku penghuni dalam menata furnitur dan pemilih jenis furnitur

Metode penelitian menggunakan metode analisis sistemik melalui Evaluasi Purna Huni (Post Occupancy Evaluation). Evaluasi purna huni (EPH) atau dikenal sebagai Post Occupancy Evaluation (POE) didefinisikan oleh Zimring dan Reizenstein (1981) sebagai pengujian efektivitas sebuah lingkungan buatan bagi kebutuhan manusia (Laurens 2005). Oleh karena itu evaluasi purna huni ini mengandalkan kebutuhan atau program pengguna sebagai kriteria atau tolok ukur keberhasilan suatu penataan lingkungan buatan melalui persepsi pengguna dalam hal ini adalah penghuni rumah susun dan hasil pengamatan spatial behavior di lapangan.

Proses evaluasi ini menjadi bagian dari desain behavior setting yang melibatkan para 
stakeholder seperti individu (penghuni) dan berbagai kelompok yang terkait dalam perencanaan dan manajemen ruang. Proses ini dapat, memberikan manfaat mendidik penghuni dalam penggunaan ruang secara bijak dan kreatif agar mendapatkan keseimbangan yang harmonis antara lingkungan sosial budaya, lingkungan buatan dan lingkungan alam.

Evaluasi Purna Huni (EPH) dapat dikelompokkan menjadi tiga kelompok yaitu evaluasi teknis, evaluasi fungsional dan evaluasi perilaku atau evaluasi behavior (Snyder 1995; Laurens 2005).

a. Evaluasi Teknis, meliputi peraturan bangunan, ketentuan teknis lain diluar peraturan serta faktor kesehatan, keselamatan dan keamanan;

b. Evaluasi Fungsional, terdiri dari dimensi fisik ruang, konfigurasi ruang dan tata perabot

c. Evaluasi Perilaku, meliputi privacy, interaksi penghuni, melalui fenomena persepsi lingkungan, pemanfaatan behavior setting dan kognisi spasial

\section{HASIL DAN PEMBAHASAN}

\section{A. Kondisi Eksisting Unit Hunian Rumah}

\section{Susun}

Terdapat 6 tipe Unit Satuan Rumah Susun yang dikembangkan pada rumah susun sederhana di KBB Kemayoran. Rumah susun ini setiap Bloknya terdiri atas 5 (lima) lantai, yaitu lantai dasar yang diperuntukkan bagi kegiatan usaha atau komersial maupun fasilitas sosial atau umum. Luasan unit satuan rumah susun yang dikembangkan adalah $18 m^{2}, 21 m^{2}, 36 m^{2}$, dan $42 m^{2}$. Unit satuan rumah susun dengan luasan $18 \mathrm{~m}^{2}$ dan $36 \mathrm{~m}^{2}$ masing-masing dikembangkan dalam 2 (dua) variasi atau tipe. Rumah susun tipe tipe 36 ini yang diteliti di Blok $A 1$ dan $A 3$, terdiri dari 6 area tangga (sub-blok). Blok ini semuanya merupakan rumah susun milik yang dibangun Tahap I. (Gambar 1.)
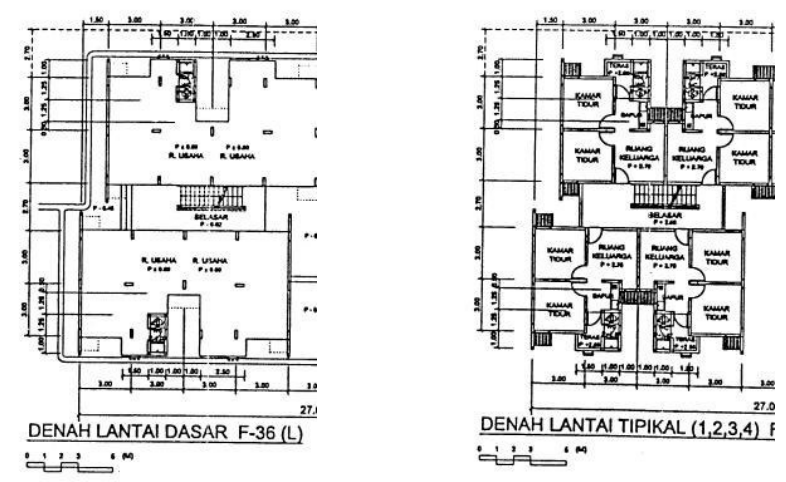

Gambar 1 Denah lantai dasar dan denah lantai tipikal T36 A (Sumber: Hasil Data Lapangan, 2011)

Tipe rumah susun 5 lantai ini berbentuk memanjang dengan koridor di bagian dalam. Lantai dasar merupakan unitunit usaha yang tiap sub-blok terdiri dari 4 unit usaha dan 2 kamar mandi. Sedangkan 
lantai 1 hingga lantai 4 merupakan unit hunian, dengan bentuk tipikal, tiap sub-blok terdiri dari 4 unit hunian.

Zonasi ruang unit hunian tipe 36 berdasarkan sifat ruang dibagi menjadi 3 (tiga) yaitu (1) zona semi publik, (2) privat dan (3) service. Sirkulasi orang dalam melakukan pergerakan aktivitas dalam unit hunian dibuat satu garis linier yang menghubungkan setiap zona dari pintu masuk hingga teras/balkon (Gambar 2)
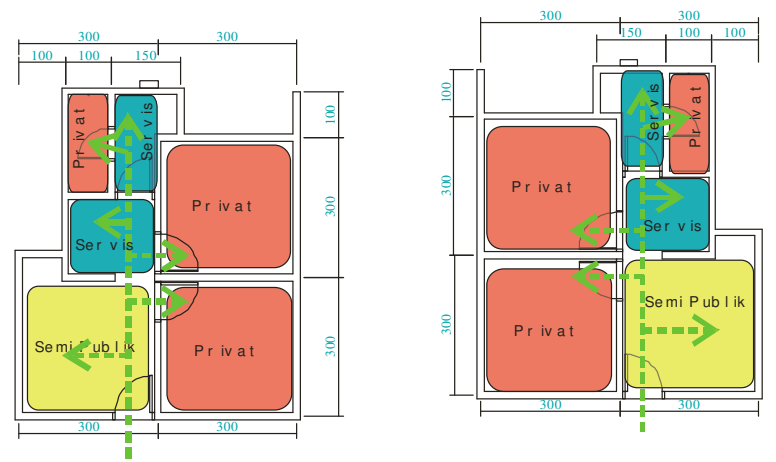

Gambar 2. Zonasi ruang hunian T36A

(Sumber: Diolah dari hasil survey lapangan, 2011)

Organisasi ruang di unit tipe T36 ini terdiri dari sebuah ruang keluarga berukuran $3 m \times 3 m+1 m \times 0,5 m$, dua buah kamar tidur (keduanya dengan ukuran $3 \mathrm{~m} \times 3 \mathrm{~m}$ ), area dapur $1,75 \mathrm{~m} \times 1 \mathrm{~m}$, dan area tangga berukuran $1 \mathrm{~m}$ x 0,5 m . (Gambar 3)
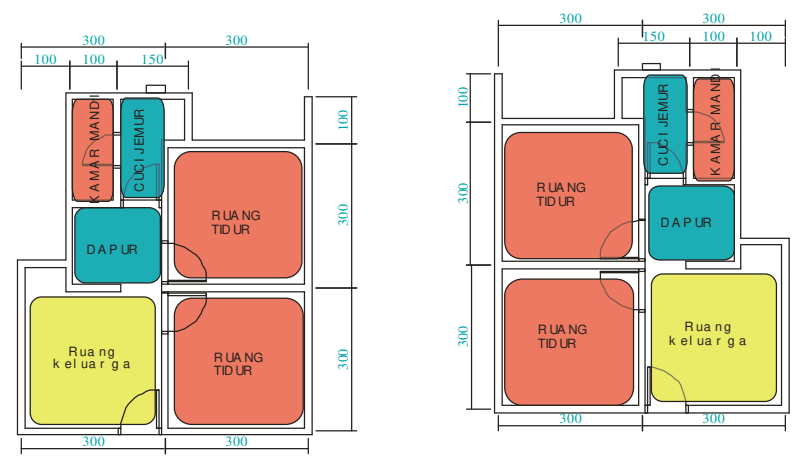

Gambar 3. Organisasi Ruang Hunian tipikal T 36 A

(Sumber: Diolah dari hasil survey lapangan, 2011)

Pola Letak Furnitur di Unit Hunian Rusun tipe 36 untuk keluarga kapasitas 4 orang (Gambar 4)

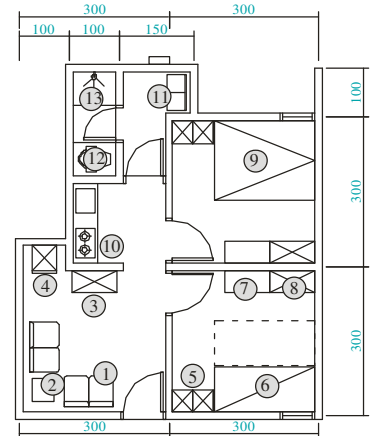

DENAHTYPE 36A

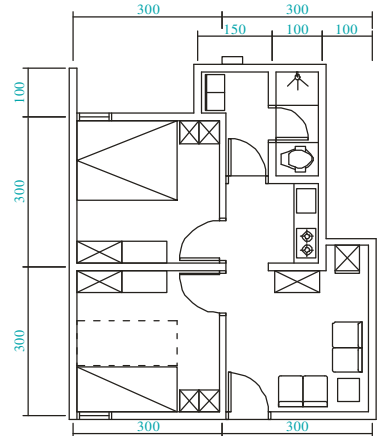

DENAHTYPE $36 \mathrm{~A}-1$

\section{Gambar 4. Pola letak furnitur}

Sumber: Diolah dari hasil survey lapangan , 2011

\section{B. Penghunian Rumah Susun T 36}

Penghunian responden terdapat 1 jiwa hingga 7 jiwa setiap unit. Penghunian 4 jiwa/unit merupakan kondisi penghunian yang paling banyak ditemukan pada penelitian ini. Kepadatan rata-rata penghunian responden adalah 9,7 m2/jiwa. Kondisi kepadatan terendah 1 jiwa/unit menghasilkan angka kepadatan 36m2/jiwa (tinggi/renggang) dan 
kondisi kepadatan tertinggi 7 jiwa/unit menghasilkan angka kepadatan 5,14 m2/jiwa (rendah/sesak).

\section{Gambaran penghuni rumah susun} berdasarkan status dan lama tinggal

Berdasarkan status tinggal terdapat 2 kategori yaitu milik dan sewa. Milik artinya penghuni secara hukum memiliki unit hunian satuan rumah susun. Sedangkan yang sewa adalah penghuni menyewa dari pemilik satuan unit hunian rumah susun. Dari 50 responden terdapat $52 \%$ yang memiliki unit hunian, dan $48 \%$ penghuni yang menyewa unit hunian (Tabel 1)

Tabel 1. Status dan Lama Tinggal

\begin{tabular}{|c|c|c|}
\hline $\begin{array}{c}\text { Lama Tinggal } \\
\text { (Tahun) }\end{array}$ & Sewa & Milik \\
\hline $1-5$ & 20 & 2 \\
\hline $6-10$ & 4 & 4 \\
\hline $11-15$ & 0 & 4 \\
\hline $16-20$ & - & 16 \\
\hline Jumlah & $48 \%$ & 24 \\
\hline$\%$ & & $52 \%$ \\
\hline
\end{tabular}

Sumber: Hasil diolah dari data lapangan, 2011

\section{Gambaran penghuni rumah susun}

\section{berdasarkan jumlah anak dalam keluarga}

Penghuni yang merupakan satu keluarga yang terdiri dari ayah, ibu dan anak menjadi perhatian peneliti. Penghuni yang bukan sebuah keluarga dengan ayah dan atau ibu serta anak, disamakan dengan keluarga yang tidak memiliki anak (jumlah anak $=0$ ). Jumlah keluarga yang memiliki 2 anak ditemukan paling banyak yaitu $40 \%$ dan lengkapnya dapat dilihat di ( Tabel 2)

\section{Tabel 2. Jumlah Anak dalam Keluarga}

\begin{tabular}{|c|c|c|c|c|c|c|}
\hline \multirow{2}{*}{} & \multicolumn{5}{|c|}{ Jumlah Anak } & \multirow{2}{*}{ Total } \\
\cline { 2 - 6 } & 0 & 1 & 2 & 3 & 4 & \\
\hline $\begin{array}{l}\text { Jumlah } \\
\text { Keluarga }\end{array}$ & 8 & 14 & 20 & 6 & 2 & 50 \\
\hline$\%$ & 16 & 28 & 40 & 12 & 4 & 100 \\
\hline
\end{tabular}

Sumber: Hasil diolah dari data lapangan, 2011

\section{E. Gambaran penghuni rumah susun}

\section{berdasarkan komposisi jenis kelamin anak}

Berdasarkan wawancara terdapat temuan bahwa responden yang memiliki anak lebih dari satu dan memiliki anak dengan jenis kelamin laki-laki dan perempuan, mengalami masalah kebutuhan ruang ketika anak beranjak dewasa, karena kamar tidur anak laki-laki \& anak perempuan yang beranjak dewasa tidak dapat disatukan lagi. Penghuni yang memiliki anak lebih dari 1 (satu) orang, kemudian dilihat profil komposisi jenis kelamin anaknya. Keluarga yang memiliki anak laki-laki dan anak perempuan terdapat 20 keluarga (53\%). Artinya keluarga dengan 2 anak yang berbeda jenis kelamin perlu mendapat perhatian lebih (Tabel 3) 
Tabel 3. Jenis Kelamin Anak dalam Keluarga

\begin{tabular}{|c|c|c|c|c|}
\hline & \multicolumn{3}{|c|}{ Jenis Kelamin } & \multirow[t]{2}{*}{ Total } \\
\hline & $\begin{array}{c}\text { Laki-laki } \\
\text { saja }\end{array}$ & $\begin{array}{c}\text { Perem } \\
\text { puan } \\
\text { saja }\end{array}$ & $\begin{array}{l}\text { Laki-laki \& } \\
\text { Perempuan }\end{array}$ & \\
\hline $\begin{array}{l}\text { Jumlah } \\
\text { Keluarga }\end{array}$ & 16 & 2 & 20 & 38 \\
\hline$\%$ & 42 & 5 & 53 & 100 \\
\hline
\end{tabular}

Sumber: Hasil diolah dari data lapangan, 2011

\section{F. Aktivitas Penghuni dan Ruang Unit Hunian}

\section{Rumah Susun}

Aktivitas penghuni di rumah susun terdiri dari kelompok aktivitas yang dilakukan oleh penghuni sehari-hari di dalam dan di luar rumah kelompok aktivitas penghuni dibagi menjadi: istirahat/tidur, berkumpul dengan keluarga, bersosialisasi, makan-minum, memasak, mandi, berpakaian \& berhias, kerja/belajar, mencuci/menjemur pakaian.

Wadah aktivitas penghuni rusun yang dilakukan di dalam unit hunian dibagi menjadi: ruang tidur/istirahat, ruang keluarga, dapur, kamar mandi, teras cuci jemur. Wadah aktivitas penghuni rusun yang dilakukan di luar unit hunian dibagi menjadi: selasar, fasilitas sosial, fasilitas umum.

\section{G. Gambaran Kondisi Eksisting Unit Hunian}

\section{Rumah Susun}

Berdasarkan analisa fisik, seluruh responden baik yang sewa maupun yang memiliki sendiri unit huniannya telah melakukan perbaikan pada beberapa aspek bangunan rusun yang telah berdiri 20 tahun (sejak tahun 1992). Perbaikan fisik dilakukan dari yang sifatnya minor seperti pengecatan ulang hingga penggantian material.

Kondisi fisik unit hunian sangat bervariasi, dari kondisi fisik yang tidak terawat hingga kondisi fisik hunian yang sangat terawat. Unit hunian yang dikelompokkan tidak terawat adalah unit hunian yang mengalami beberapa kerusakan fisik yang menyebabkan menurunnya kualitas kenyamanan seperti: langit-langit bocor, permukaan dinding mengelupas (bagian semen runtuh), utilitas yang rusak (tidak beroperasi dalam waktu lama)

Unit hunian yang dikelompokkan terawat adalah unit hunian yang telah dilakukan perbaikan fisik yang menyebabkan meningkatnya kualitas kenyamanan penghuni. Unit hunian yang terawat yang menghasilkan ruang yang teratur, kualitas material finishing yang baik dapat menghadirkan kesan bersih, indah, rapi, sehingga penghuni merasa nyaman tinggal di dalamnya

\section{H. Gambaran Perilaku Penghuni di Ruang Keluarga}

Ruang keluarga merupakan ruang yang paling penting dalam unit hunian rusun. 
Penghuni menggunakan ruang ini untuk berbagai aktivitas sehari-hari di rumah susun Sirkulasi penghuni di ruang ini paling padat terjadi di ruang ini. Untuk kegiatan berkumpul dengan keluarga, penghuni melengkapi ruang ini dengan fasilitas duduk seperti sofa, kursi, bantal, dan karpet. Untuk menghindari ruang ini menjadi sempit, maka sebagaian penghuni (47\%) menghindari penggunaan sofa. Kegiatan berkumpul dengan keluarga biasanya dilakukan sambil nonton TV, sehingga selain fasilitas duduk, dilengkapi pula fasilitas rekreasi seperti TV, DVD player, Audio system, dan sebagainya. Ruang keluarga ini sekaligus juga sebagai ruang makan, namun untuk fasilitas furniturnya, sebagian besar penghuni (64\%) tidak menggunakan meja untuk aktivitas makan agar ruang keluarga tidak sempit. Untuk keluarga yang memiliki anak lebih dari 1 (satu) dan memiliki anak lakilaki diatas 15 tahun, biasanya juga menggunakan ruang keluarga ini sebagai kamar tidur anak laki-laki. Tentu hal ini menjadi masalah karena privasi anak laki-laki berkurang dan juga kenyamanan keluarga dalam beraktivitas di ruang keluarga. Orang tua biasanya menempatkan tempat istirahat bagi anak laki-laki di ruang keluarga karena alasan anak laki-laki lebih kuat dan lebih banyak beraktivitas di luar rumah dibandingkan anak perempuan. Untuk aktivitas tidur anak laki-laki menggunakan kasur lipat.

Ruang keluarga juga banyak digunakan anak-anak sebagai tempat mereka belajar. Dalam beraktivitas belajar, anak-anak biasanya menggunakan meja rendah dengan sistem lipat yang mudah untuk simpan dan pakai. Ruang keluarga juga berfungsi sebagai tempat melakukan persiapan dan penyajian setelah masak. Karena ruang dapur sempit, biasanya para ibu menggunakan ruang keluarga sebagai tempat menyiapkan bahanbahan makanan sebelum diolah atau dimasak.

\section{Gambaran Perilaku Penghuni di Ruang Tidur}

Penghuni menggunakan kamar tidur untuk kegiatan istirahat dan tidur dengan memfasilitasi ruang ini dengan ranjang ganda untuk orang tua dan ranjang tunggal susun untuk anak-anak. Sebagian penghuni hanya menggunakan kasur untuk alas tidur (tanpa ranjang), dengan alasan mudah untuk pindahpindah (terutama penyewa) dan menghindari kesan ruang sempit.

Di ruang ini penghuni juga menempatkan lemari dan laci pakaian. Sebagian melengkapi dengan meja rias, fasiltas para ibu dan anak perempuan untuk berhias diri. Untuk kamar 
tidur anak, biasanya dilengkapi fasilitas belajar seperti meja tulis, kursi dan meja komputer. Untuk menambah kenyamanan, penghuni sebagaian besar menambahkan fasilitas kipas angin dan pendingin ruangan (AC) pada kamar tidurnya.

Sebagian penghuni menggunakan kamar tidur untuk rekreasi (menonton TV). Kamar tidur juga menjadi tempat menyimpan barang-barang dan hal ini mengganggu sirkulasi dan kenyamanan dalam beraktivitas di kamar tidur.

\section{J. Gambaran Perilaku Penghuni di Dapur}

Penghuni merasakan kurangnya kenyamanan beraktivitas di dapur yang hanya berukuran bersih 1,75 $\mathrm{m} \times 1 \mathrm{~m}$. Dapur penghuni awalnya hanya dilengkapi bak cuci piring dan kompor yang mendapat aliran gas dari Perum Gas Negara. Penghuni melakukan aktivitas memasak, mencuci piring, menyimpan alatalat masak, makan dan minum di dapur yang sangat terbatas ini.

\section{K. Gambaran Perilaku Penghuni di Kamar}

\section{Mandi}

Kamar mandi memiliki luas $1 \mathrm{~m}$ x $2 \mathrm{~m}$ dan sejak awal dilengkapi dengan bak air dan closet jongkok. Sebagain besar masih menggunakan closet jongkok dengan alasan ruang yang sempit dan budaya. Selain ukuran luas ruang yang terbatas, letaknya yang agak terpisah di bagian belakang sering menjadi keluhan para penghuni. Penghuni sebagain besar menambah fasilitas rak gantung untuk menyimpan alat-alat dan keperluan untuk mandi.

\section{Gambaran Perilaku Penghuni di Area Servis}

Area servis awal dibangun semi terbuka, dengan hanya dinaungi langit-langit arsitektural dan tanpa dinding. Ruang yang disebut penghuni sebagai teras ini digunakan sebagai tempat melakukan aktivitas mencuci, jemur, menyimpan alat cuci jemur pakaian, dan alat kebersihan. Responden ada yang menambahkan unsur dinding semi tertutup pada area servis yakni menggunakan konstruksi kusen alumunium jendela kaca. Ada pula yang menambahkan teralis besi untuk meningkatkan keamanan. Ruang servis yang telah dimodifikasi ini biasanya ditambahkan pula fungsi gudang di dalamnya.

\section{Gambaran Perilaku Memilih Jenis Furnitur}

Alasan responden memilih jenis furnitur dikelompokkan menjadi 6 kategori: fungsi, harga, bentuk, jenis material, ukuran dan 
kekuatan konstruksi, dengan pertimbangan skala prioritas. Sebagian besar responcen memilih aspek fungsi sebagai prioritas pertama dalam memilih jenis furnitur. Berdasarkan pengamatan di lapangan, penghuni tidak melakukan perencanaan spasial yang matang dan menyeluruh dalam menentukan pola letak dan memilih jenis furnitur (seluruh responden tidak pernah melakukan konsultasi dengan ahli untuk membantu memecahkan masalah desain unit hunian) . Mereka cenderung membeli furnitur secara parsial yang sesuai kebutuhan dan keinginan namun cukup mempertimbangkan aspek luas dan kenyamanan ruang.

Responden sebagian besar memilih jenis furnitur lepas (loose furniture) dan membelinya secara bertahap. Furnitur lepas yang bersifat satuan, yang diletakkan di lantai (bukan di gantung di dinding), bervariasi bentuk, warna, material, ukuran lebih mendominasi dan mengurangi keleluasaan ruang gerak penghuni.

Penghuni sewa biasanya lebih selektif dalam memilih jenis furnitur. Penyewa memilih jenis furniture yang lebih ringan, bentuk sederhana dan ringan sehingga mudah untuk dipindah-pindah. Penyewa juga memperhitungkan jumlah furnitur yang mereka bawa ke rusun agar tidak terlalu banyak dan memakan waktu pada saat pindah tempat tinggal ke tempat lain di kemudian hari.

\section{N. Gambaran Perilaku Meletakkan Furnitur}

Perilaku penghuni dalam meletakkan jenis furnitur merupakan bentuk kesadaran penghuni tentang fungsi tiap ruang dan kedekatan setiap aktivitas dalam ruang. Hasil penelitian pada responden menunjukkan mayoritas (72\%) responden sadar akan fungsi tiap ruang dan meletakkan furnitur yang sesuai untuk menunjang aktivitas di ruang tersebut

\section{O. Gambaran Perilaku Menata Ulang \\ Eleman Ruang}

Rumah susun didirikan oleh Perumnas menggunakan bahan material arsitektur berupa lantai beton plester, dinding bata plester dan langit-langit beton plester (ekspos). Untuk dinding dan langit-langit paling banyak diberi finishing cat tembok. Seiring dengan berkembangnya kebutuhan dan keinginan untuk meningkatkan kenyamanan para penghuni menambahkan atau mengganti material interior.

P. Gambaran Persepsi Penghuni Rumah Susun 
Hasil angket menunjukkan bahwa $72 \%$ responden (baik yang berstatus sewa maupun milik) merasa betah dan ingin tinggal lebih lama di rusun Kemayoran. Responden sebanyak 20\% dapat bertahan dalam kondisi sekarang dan sisanya $8 \%$ merasa tidak betah dan ingin mencari tempat tinggal lain

Penghuni yang tinggal diatas 10 tahun merasa betah dan ingin tinggal lebih lama di rusun. Mayoritas penghuni memiliki alasan lokasi rusun yang strategis di tengah kota Jakarta sebagai alasan utama tinggal di Rusun Kemayoran.

\section{Q. Kenyamanan penghuni dalam melakukan aktivitas di dalam unit hunian}

Penghuni dalam melakukan aktivitas sehari-hari di dalam unit huniannya membutuhkan kenyamanan untuk bergerak, yang mana angka kenyamanan dengan skala angka terendah $1=$ sangat tidak nyaman dan angka tertinggi 5=sangat nyaman. Hasil penelitian melalui angket menghasilkan angka kenyamanan responden, dengan nilai tertinggi dalam aktivitas istirahat/tidur 3,84 (Tabel 4.). Angka kenyamanan terendah terjadi di aktivitas memasak 3,12. Sedangkan angka kenyamanan dalam aktivitas secara umum menunjukkan angka kenyamanan 3,56. Yang artinya artinya responden secara umum memiliki tingkat kenyamanan sedang dalam melakukan aktivitas sehari-hari di unit huniannya. Penghuni dapat beradaptasi dengan lingkungan unit hunian rusun yang terbatas.

Tabel 4. Tingkat kenyamanan aktivitas penghuni

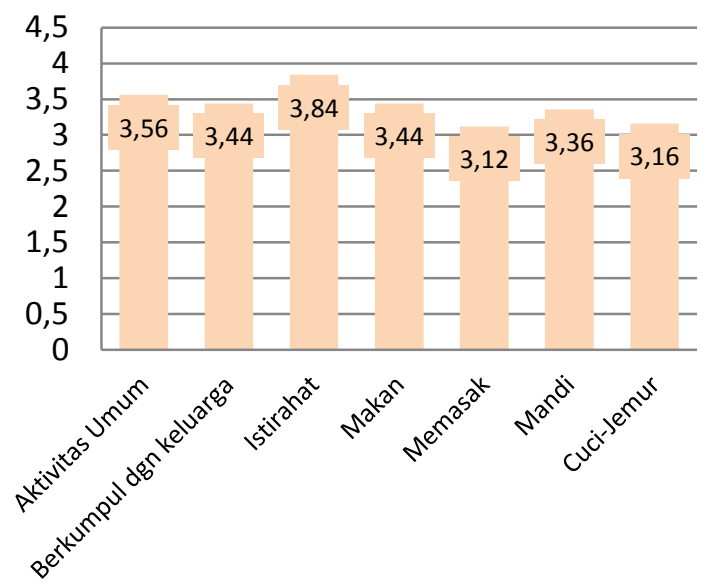

Sumber: Hasil data lapangan, 2011

\section{SIMPULAN}

Berdasarkan hasil penelitian ini maka dapat dirumuskan pertimbangan pengembangan desain unit hunian rumah susun tipe 36

1) Perilaku penghuni rusun tipe 36 yang cukup kompleks dan bervariatif, menjadi pertimbangan yang penting dalam menentukan pola yang tepat dan dapat dibuat beberapa pola untuk setiap karakteristik kelompok penghuni.

2) Kapasitas optimal untuk tipe 36 adalah 4 orang yang menghasilkan kepadatan 
9m2/jiwa sehingga memenuhi standar PU (8 $\mathrm{m} 2 /$ jiwa)

3) Kondisi penghuni tipe 36 yang memiliki tingkat kompleksitas masalah lebih tinggi adalah keluarga yang terdiri dari ayah, ibu, anak laki-laki dan anak perempuan dibanding keluarga yang memiliki 2 anak dengan jenis kelamin sama (laki-laki atau perempuan saja). Ini berdasarkan hasil wawancara bahwa keluarga dengan karakteristik seperti ini mengalami permasalahan kebutuhan spasial untuk ruang tidur anak laki dan perempuan yang mana tidak bisa digabung lagi pada usia anak mulai remaja.

4) Penghunian unit rumah susun dari aspek fungsional, penghuni dapat beraktivitas cukup nyaman di lingkungan ruang dalam yang dapat mengakomodasi kegiatan rutin keseharian.

5) Penghuni rumah susun sebagian besar cukup baik beradaptasi dan masih ingin tinggal lebih lama di lingkungan rumah susun.

6) Penghunian unit rumah susun memerlukan perencanaan pemilihan jenis furnitur yang menyeluruh dan berorientasi ke depan dengan pertimbangan aspek fungsi, harga, bentuk, jenis material, ukuran dan kekuatan konstruksi
7) Untuk meningkatkan kenyamanan jangka pendek (pengembangan desain eksisting) dapat dilakukan dengan menata ulang bahan finishing, pemilihan jenis funitur yang tepat dan menata ulang letak furnitur. Jangka menengah dengan merencanakan ulang jenis furnitur yang dibutuhkan dan untuk jangka panjang menata ulang partisi ruang dan furnitur untuk mendapatkan kenyamanan yang optimal.

8) Penggunaan material finishing yang berkualitas cukup baik perlu diterapkan pada unit hunian agar tidak terjadi tambal sulam perbaikan yang akhirnya memakan biaya yang cukup besar.

\section{DAFTAR PUSTAKA}

Bell, P. A., J. D. Fisher, R. J., and Loomis. 1978. Environment Psychology. W. B. Sauders Co. Phil.

Deliyanto. Bambang, 2000. Tindak

Penyesuaian diri Warga Jakarta Dalam Menghuni Rumah Susun Sederhana Dan Lingkungannya - studi kasus Rumah Susun Klender dan Rumah Susun Kemayoran". Proyek Pengkajian dan Penelitian Ilmu Pengetahuan Dasar. Direktorat PPPM, DIKTI, Depdiknas. 
Krech, David., Richard S Crutchfield, and

Egerton L Ballachey. 1962. Individual In

Society .Textbook of Social Psychology,

New York: McGraw-Hill.

Laurens, Joyce Marcella. 2004. Arsitektur dan

Perilaku Manusia ", Jakarta : Grasindo,

Zeisel, John . 1981. Inquiry by design : Tools

For Environment Behavior Research.

Monterey, California: Brooks / Cole

Publishing Company . 